\title{
Influência da variação da velocidade de rotação e do tipo de cimento nas propriedades de argamassas de revestimento nos estados fresco e endurecido
}

\section{(Influence of rotational speed and type of cement in the fresh and hardened properties of rendering mortars)}

\author{
D. R. Torres, R. C.O.Romano*, R. G. Pileggi \\ Departamento de Engenharia Civil, Escola Politécnica, Universidade de S. Paulo, \\ Av. Prof. Almeida Prado 83, S. Paulo, SP 05424-970 \\ rcorjau@gmail.com
}

\begin{abstract}
Resumo
A etapa de mistura influencia as condições de execução do revestimento de argamassa, visto que desde o primeiro contato dos materiais sólidos com água uma série de eventos de aglomeração e desaglomeração no sistema é verificada. Acontece que durante o processamento das argamassas em obra a utilização de equipamentos com distintos mecanismos de mistura pode modificar o desempenho do sistema de revestimento. Este trabalho foi realizado com o objetivo de avaliar a influência da condição de mistura durante o processamento de argamassas aditivadas com incorporador de ar e formuladas com diferentes tipos de cimento. As misturas foram realizadas em um reômetro rotacional variando-se a velocidade de rotação, porém mantendo-se o tempo total de batimento. Reometria de mistura, ciclo de cisalhamento e teor de ar incorporado foram as propriedades avaliadas no estado fresco, enquanto porosidade, resistência mecânica, módulo de elasticidade e permeabilidade ao ar foram utilizados para avaliação do estado endurecido. Com base nos resultados obtidos pôde-se afirmar que a variação da velocidade de rotação e o tipo de cimento utilizado impactaram as propriedades das composições nos estados fresco e endurecido.
\end{abstract}

Palavras-chave: argamassa, CPIIF, CPIII, energia de mistura, reômetro.

\begin{abstract}
The mixing stage is one of the most important step for the execution of the rendering mortar, since from the first contact of the solid materials with water a series of agglomeration and deagglomeration events in the system is verified. However, during the mortar processing in the buildings the use of different equipments, with distinct mixing concepts, makes this stage very uncontrolled. The main purpose of this work was to evaluate the influence of mixing condition during the processing of mortars with addition of air-entraining agent and formulated with different kind of Portland cement. The mixing was performed on a rotational rheometer in different rotational speed, but maintaining the total time of shear. Mixing and shear rheometry, and air-incorporation were the properties evaluated in the fresh state, while porosity, mechanical strength, dynamic elasticity modulus and air-permeability were used to evaluate the hardened state. Based on the obtained results, it could be stated that the variation of the rotational speed and the type of cement used impacted the properties of the compositions in the fresh and hardened states, mainly due to changes in the air-volume incorporated and, consequently, in the total porosity generated in the mortars.
\end{abstract}

Keywords: mortar, CPIIF, CPIII, energy of mixing, rheometer.

\section{INTRODUÇÃO}

Argamassas de revestimento são materiais multifásicos e heterogêneos, compostas por areia (natural ou britada), ligantes (hidráulico ou aéreo) e adições minerais (inertes ou reativas) [1]. No entanto, durante o seu preparo nas obras a mistura com a água deve tornar o conjunto homogêneo e contínuo, resultando em um material que flua sem que ocorra segregação das fases [1-3]. Acontece que mesmo com o preciso controle na dosagem das matérias-primas, ainda há considerável variabilidade na etapa de mistura, rápida perda da trabalhabilidade, instabilidade do ar, entre outros fatores, que afetam de forma indesejada o desenvolvimento da microestrutura do material aplicado alterando o seu desempenho em uso $[4,5]$. A primeira etapa da mistura consiste na adsorção da água na superfície das partículas e ocorre a formação dos aglomerados, devido às forças de interação de van de Waals, forças eletrostáticas entre posições de sítios com cargas opostas e forte interação ou ligação envolvendo as moléculas de água ou hidratos [4]. Essa aglomeração é responsável pela retenção de parte da água necessária para a mistura que, caso a energia de cisalhamento não seja suficiente para desaglomeração, fica indisponível para hidratar a superfície das partículas de cimento e fluidificar a mistura [6]. A caracterização da mistura, portanto, pode ser um indicativo da qualidade e da produtividade da argamassa 
em obra: maiores energias necessárias para o processamento das argamassas podem indicar menor produtividade, pois necessitam de maiores tempos de mistura ou de maiores esforços do profissional responsável pelo amassamento.

Em obra as argamassas são misturadas utilizando-se diferentes equipamentos (betoneiras, misturadores de eixo vertical e de eixo horizontal, etc.), com distintos mecanismos para a homogeneização da suspensão; assim, dificilmente é atingido o mesmo nível de desaglomeração e incorporação de ar quando se comparam distintas bateladas, devido à alteração da eficiência de cada equipamento [4]. Adicionalmente, pouca discussão é encontrada em literatura sobre o efeito do tipo de cimento nas propriedades de argamassas, seja no estado fresco ou endurecido. Porém, o tipo de ligante utilizado na formulação é uma variável que afeta a qualidade do revestimento, pois altera a dissolução das fases, reação química, consolidação, interação com os aditivos, entre outras [7]. Sendo assim, este trabalho foi realizado com o objetivo de avaliar o impacto da variação da velocidade de rotação imposta durante o processamento de argamassas de revestimento formuladas com cimentos CPIIF ou CPIII e aditivadas com incorporador de ar, nos estados fresco e endurecido.

\section{PROCEDIMENTO EXPERIMENTAL}

Materiais: foram utilizadas areias normalizadas e cimentos Portland tipo CPIIF (Cimpor) e CPIII (CSN), com as propriedades físicas e distribuição granulométrica conforme ilustrado nas Fig. 1 e Tabela I. O cimento de escória apresentou maior área superficial específica (ASE), menor densidade real e distribuição granulométrica com partículas mais grossas, comparado ao cimento composto com filler calcário. Esses resultados poderiam gerar dúvida com relação à confiabilidade dos ensaios, visto que é mais comum um material mais grosso apresentar menor área superficial. No entanto, essa correlação é real para materiais com a mesma composição mineralógica: por exemplo, se uma brita é moída e peneirada em diferentes granulometrias, as frações mais finas apresentam ASE maior. No caso dos cimentos, por se tratarem de materiais comerciais, não se tem a característica

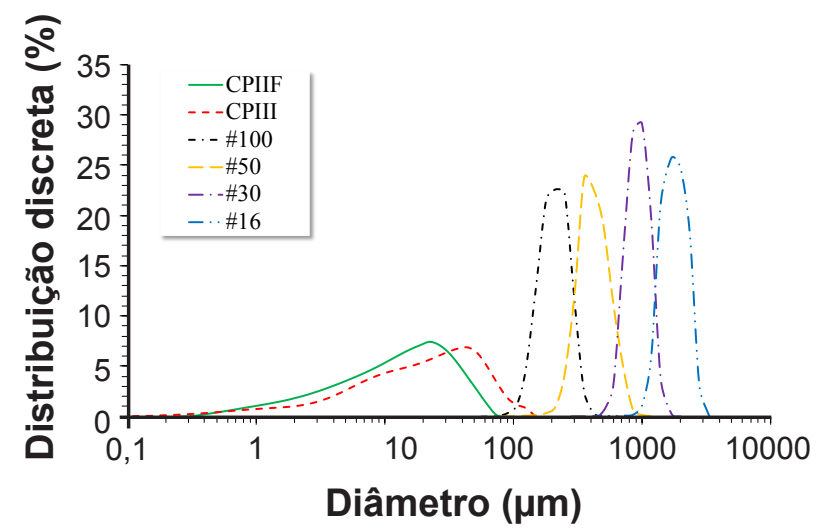

Figura 1: Distribuição granulométrica dos cimentos e areias utilizados na formulação das argamassas.

[Figure 1: Particle size distribution curves of cement and sand used in the mortar formulation.]
Tabela I - Densidade e área superficial das máterias-primas. [Table I-Real density and specific surface area of raw materials.]

\begin{tabular}{cccc}
\hline $\begin{array}{c}\text { Matéria- } \\
\text { prima }\end{array}$ & $\begin{array}{c}\text { Densidade } \\
\text { real } \\
\left(\mathrm{g} / \mathrm{cm}^{3}\right)\end{array}$ & $\begin{array}{c}\text { Área } \\
\text { superficial } \\
\text { específica BET } \\
\left(\mathrm{m}^{2} / \mathrm{g}\right)\end{array}$ & $\begin{array}{c}\text { Área } \\
\text { superficial } \\
\text { volumétrica } \\
\left(\mathrm{m}^{2} / \mathrm{cm}^{3}\right)\end{array}$ \\
\hline CPIIF & $\begin{array}{c}3,01 \pm \\
0,01\end{array}$ & 1,75 & 5,26 \\
CPIII & $\begin{array}{c}2,83 \pm \\
0,03\end{array}$ & 2,02 & 5,72 \\
Areia \#100 & $\begin{array}{c}2,61 \pm \\
0,02\end{array}$ & 0,60 & 1,57 \\
Areia \#50 & $\begin{array}{c}2,60 \pm \\
0,01\end{array}$ & 0,59 & 1,53 \\
Areia \#30 & $\begin{array}{c}2,58 \pm \\
0,01\end{array}$ & 0,58 & 1,47 \\
Areia \#16 & $\begin{array}{c}2,59 \pm \\
0,01\end{array}$ & 0,58 & 1,50 \\
& & \\
\hline
\end{tabular}

exata do filler utilizado no CPIIF ou da escória adicionada no CPIII. Por isso, não se pode fazer inferências com relação à granulometria. $O$ valor da área superficial volumétrica (relação entre a ASE x densidade real) foi maior no cimento de escória, o que pode afetar de forma indesejada a consistência dos produtos misturados com a mesma quantidade de água. No caso das areias, por outro lado, a única diferença considerável foi a distribuição granulométrica, visto que se tratam de agregados provenientes da mesma rocha, britados e separados em peneiras com distintas aberturas.

As argamassas foram formuladas com as quatro frações da areia em proporções iguais, conforme sugerido pela NBR 7214/15 [8], e cimento Portland, utilizando-se uma relação areia:cimento de 1:3 (em massa). As distribuições granulométricas das composições são apresentadas na Fig. 2, e na Tabela II são apresentados os parâmetros de mobilidade e empacotamento de partículas das composições, levando-se em consideração que as argamassas foram misturadas com 15\% de água em relação à massa total de pó. Deve ser salientado que para se calcular o valor de MPT (espessura da camada

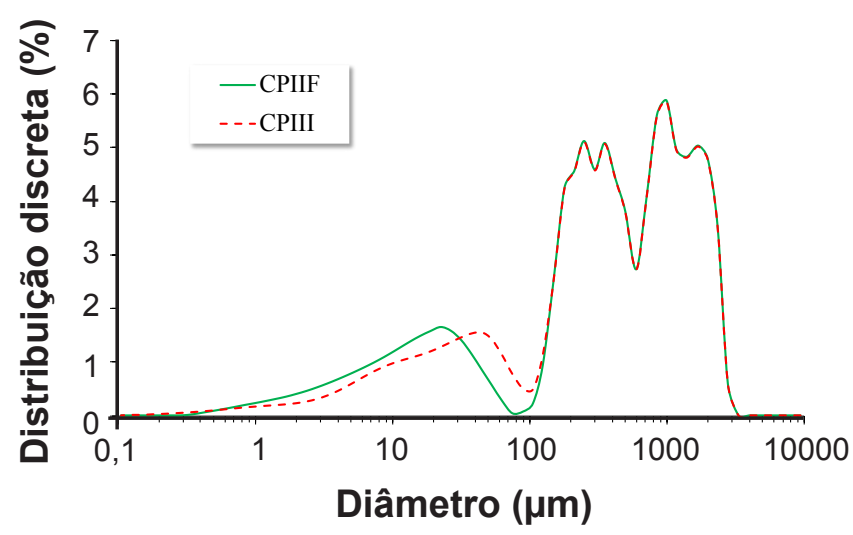

Figura 2: Distribuições granulométricas das argamassas. [Figure 2: Mortars particle size distribution curves.] 
Tabela II - Parâmetros de mobilidade e empacotamento de partículas das composições.

[Table II - Mobility and packing particles parameters of the compositions.]

\begin{tabular}{lcc}
\hline Parâmetro & CPIIF & CPIII \\
\hline Porosidade de empacotamento $(\%)$ & 11,8 & 11,4 \\
Área superficial volumétrica $\left(\mathrm{m}^{2} / \mathrm{cm}^{3}\right)$ & 2,36 & 2,51 \\
Área superficial específica $\left(\mathrm{g} / \mathrm{cm}^{3}\right)$ & 0,88 & 0,95 \\
Densidade do pó $\left(\mathrm{g} / \mathrm{cm}^{3}\right)$ & 2,69 & 2,65 \\
Densidade da argamassa $\left(\mathrm{g} / \mathrm{cm}^{3}\right)$ & 2,20 & 2,18 \\
$\begin{array}{l}\text { Distância de separação entre as } \\
\text { partículas finas - IPS }(\mu \mathrm{m})\end{array}$ & 0,63 & 0,55 \\
$\begin{array}{l}\text { Espessura da camada de pasta entre os } \\
\text { agregados - MPT }(\mu \mathrm{m}) *\end{array}$ & 0,77 & 0,79 \\
* Calculado sem levar em consideração o volume de ar incorporado. &
\end{tabular}

de pasta entre os agregados) não se levou em consideração o volume de ar incorporado nas argamassas, visto que este foi alterado em função da condição de mistura utilizada. A distribuição granulométrica dos agregados foi mantida constante, mas a porção mais fina $(<100 \mu \mathrm{m})$ foi alterada em função das diferenças de tamanho de partículas dos cimentos (Fig. 2). O uso de elevada quantidade de cimento foi adotado para garantir um volume adequado de pasta nas argamassas, pois as areias empregadas no estudo possuíram baixo teor de partículas finas. Foi utilizado aditivo incorporador de ar à base de lauril sulfato de sódio, no teor de $0,0025 \% \mathrm{em}$ relação à massa de cimento, com o intuito de melhorar a trabalhabilidade, sendo este procedimento adotado para a formulação de argamassas de revestimento industrializadas.

Mistura das argamassas - reometria de mistura: os pós secos foram pesados e homogeneizados antes da mistura com água. Todo o pó $(4 \mathrm{~kg})$ foi adicionado na cuba de um reômetro tipo planetário (Pheso, Sciranda), conforme utilizado em [4], e a água adicionada com vazão constante de $45 \mathrm{~mL} / \mathrm{s}$. Durante a mistura, a velocidade de rotação foi mantida constante nos níveis propostos $(125,250,500$ ou $1000 \mathrm{rpm}$ ) por $3 \mathrm{~min}$, conforme ilustrado na Fig. 3. Desta forma, apesar do tempo de cisalhamento nas argamassas ser o mesmo, a energia imposta à massa teve variação e o impacto nos estados fresco e endurecido foi quantificado. Como todas as argamassas foram misturadas pelo mesmo tempo, a quantidade de voltas da raquete sobre o próprio eixo foi distinta e dependente da velocidade de rotação. Após 3 min de cisalhamento, foram impostas 1390, 2793, 5588 e 11148 voltas, respectivamente, nas velocidades de 125, 250, 500 e 1000 rpm. Com o intuito de facilitar a compreensão dos resultados, a variação da velocidade de rotação e a resposta de cada argamassa à mistura foi definida como a estimativa da energia para o processamento (EEP), quantificada a partir da determinação da área sobre a curva de torque $v s$ tempo.

Métodos de ensaio. Densidade e ar incorporado: o ensaio foi realizado de acordo com a NBR 13278/05 [9] e os valores foram calculados a partir da densidade real do pó (obtida por

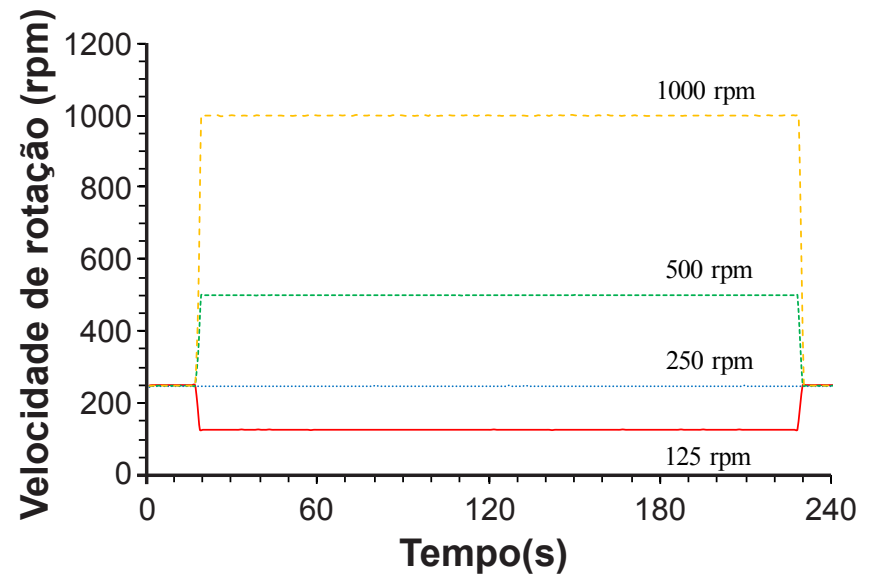

Figura 3: Programação utilizada para o processamento das argamassas.

[Figure 3: Program used to mix/evaluate the fresh state of the mortars.]

picnometria de gás hélio). Porosidade - ensaio de imersão de Arquimedes: a massa dos corpos de prova secos $\left(\mathrm{m}_{\mathrm{s}}\right)$ foi medida e as amostras foram submetidas a vácuo por $2 \mathrm{~h}$ e, então, imersas em água para forçar a intrusão nos poros. Em seguida, as massas imersas $\left(\mathrm{m}_{\mathrm{i}}\right)$ e úmidas $\left(\mathrm{m}_{\mathrm{u}}\right)$ foram quantificadas e as porosidades foram calculadas a partir das equações:

$$
\begin{aligned}
& \operatorname{PA}(\%)=\frac{m_{u}-m_{i}}{m_{u}-m_{s}} \times 100 \% \\
& \operatorname{PT~}(\%)=\left(1-\rho_{\text {REL }}\right) \times 100 \%
\end{aligned}
$$

onde, PA é a porosidade aparente, PT é a porosidade total e $\mathrm{Q}_{\mathrm{REL}}$ é a densidade relativa resultante dos pós que compuseram as argamassas. Módulo de elasticidade dinâmico: a medida foi realizada de acordo com NBR 15630/09 [10]. Para tanto, foi utilizado um equipamento ultrassônico 'pulsoeco' (Pundit), com transdutores de $200 \mathrm{kHz}$ e secção transversal circular com diâmetro de $20 \mathrm{~mm}$ (acoplados com gel na superfície dos corpos de prova). Resistência à tração na compressão diametral: foi determinada em uma máquina de ensaio universal (Instron, mod. 5569). O ensaio foi realizado seguindo a NBR 7222/11 [11], em corpos de prova com diâmetro de $50 \mathrm{~mm}$ e altura de $60 \mathrm{~mm}$. O teste foi realizado com controle de carregamento contínuo com taxa de carregamento de $0,05 \pm 0,02 \mathrm{MPa} / \mathrm{s}$. Permeabilidade ao ar: foi quantificada a partir da técnica de decaimento de vácuo - vacuum decay $[12,13]$. Neste método a diferença entre a pressão atmosférica e a pressão interna na câmara de ensaio produziu um fluxo não estacionário dentro do corpo de prova, durante um intervalo de tempo. Tal tempo foi, então, quantificado e os resultados de $\mathrm{k}_{1}$ (constante de permeabilidade darcyana) foram obtidos a partir da equação de Forchheimer [14, 15]. Os ensaios no estado endurecido foram realizados após cura por 28 dias e os corpos de prova foram curados a $23{ }^{\circ} \mathrm{C}$, em atmosfera com umidade relativa de $98 \%$. 

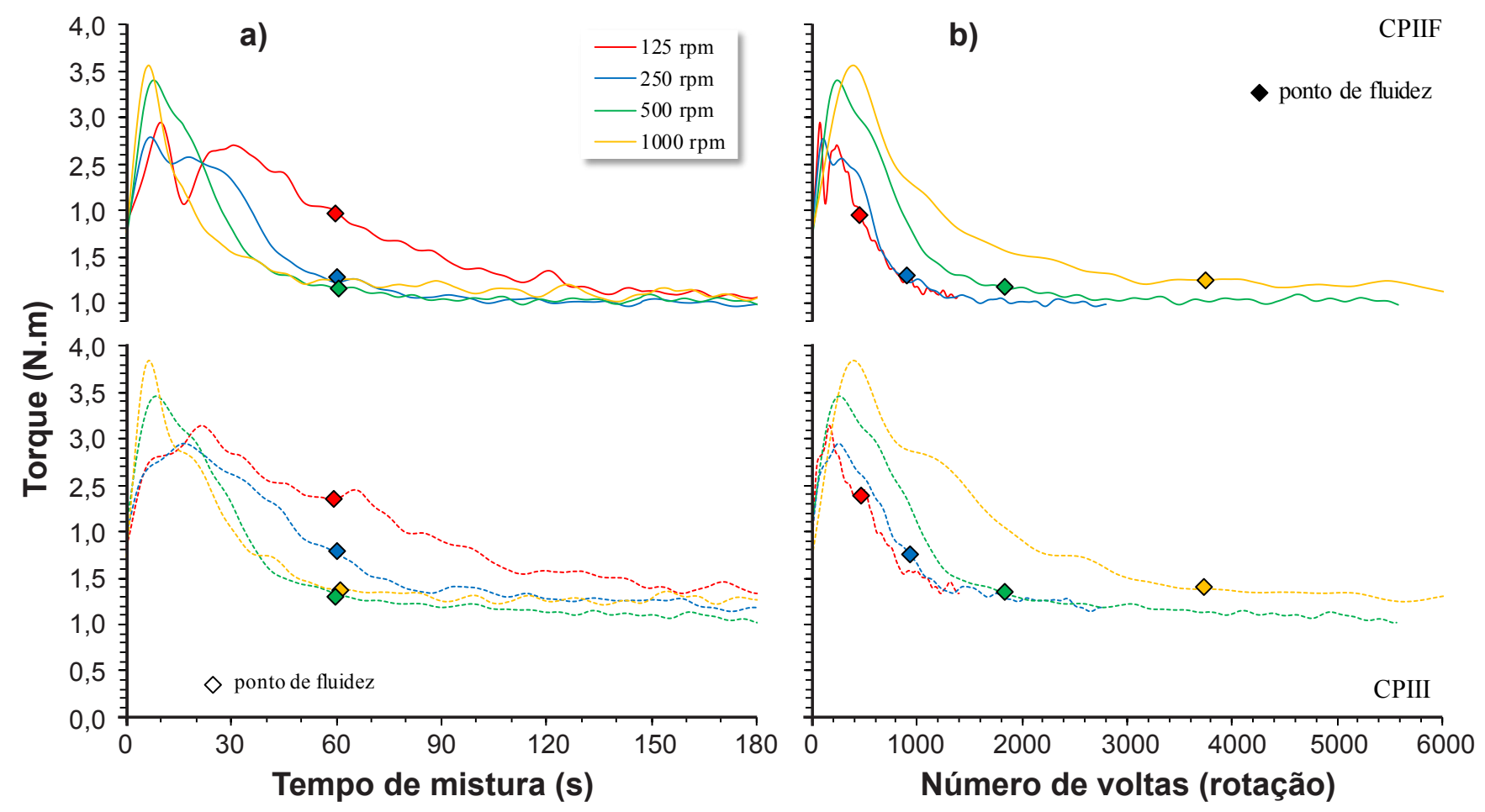

Figura 4: Perfis das curvas de mistura das argamassas em função do tempo de cisalhamento (a) e do número de voltas da raquete (b). Acima estão os resultados das argamassas formuladas com cimento CPIIF e abaixo com CPIII.

[Figure 4: Profiles of the mixing curves of the mortars as a function of the shear time (a), and the number of revolutions of paddle ( $b$ ). Above are the results for the mortars formulated with CPIIF and bellow with CPIII.]

Tabela III - Alterações no teor de ar incorporado e valores estimados das energias necessárias para o processamento de cada argamassa (EEP).

[Table III - Changes in the air-incorporation content and the estimated values of energy to processing the mortars.]

\begin{tabular}{ccccc}
\hline $\begin{array}{c}\text { Rotação } \\
(\mathrm{rpm})\end{array}$ & \multicolumn{2}{c}{ Ar incorporado (\%) } & \multicolumn{3}{c}{$\begin{array}{c}\text { Estimativa } \\
\text { da energia de } \\
\text { processamento } \\
\text { (N.m.s) }\end{array}$} \\
& CPIIF & CPIII & CPIIF & CPIII \\
\hline 125 & $11,9 \pm 0,07$ & $10,9 \pm 0,42$ & 304,1 & 365,8 \\
250 & $13,2 \pm 0,21$ & $13,2 \pm 0,59$ & 250,1 & 306,5 \\
500 & $14,8 \pm 0,66$ & $16,0 \pm 0,29$ & 249,5 & 275,0 \\
1000 & $16,6 \pm 0,93$ & $15,7 \pm 0,05$ & 248,1 & 288,5 \\
\hline
\end{tabular}

\section{RESULTADOS E DISCUSSÃO}

\section{Reometria de mistura}

A mistura de materiais cimentícios teve início na homogeneização dos constituintes anidros, ou seja, após a pesagem os pós foram misturados, visto que argamassas são sistemas compostos por partículas de diversos tamanhos [4]. A principal função da mistura é o rompimento dos aglomerados formados pela introdução da água, sendo este processo afetado pela velocidade de cisalhamento imposta ao material durante a mistura. Para discussão dos resultados de reometria de mistura, os principais parâmetros avaliados foram torque máximo atingido (referente ao ponto de máxima coesão), tempo para atingir a constância no torque, torque final (que apresenta relação com a consistência) e área abaixo das curvas de mistura, relacionada com a estimativa da energia de processamento (EEP) e indicou a energia dissipada no processo de mistura. No entanto, a definição de tais parâmetros não é trivial e para a determinação dos eventos com maior precisão optou-se por suavizar as curvas de torque e correlacioná-las com o tempo de mistura (Fig. 4a) e com o número de voltas da raquete sobre o próprio eixo (Fig. 4b). Em ambos os casos, o símbolo $\diamond$ ilustra o ponto de fluidez das argamassas determinado conforme descrito em [16] a partir do método da primeira derivada do torque. Na Tabela III são apresentados o teor de ar incorporado e a estimativa da energia para o processamento das argamassas (EEP).

Adotou-se a comparação em função do número de voltas da raquete pois quando se mistura duas argamassas em um único equipamento, mas com velocidades de rotação distintas, a imposição do cisalhamento é diferenciada, ou seja, quanto maior a velocidade maior o número de voltas do instrumento cisalhante para um mesmo tempo. Constatouse que houve alteração na intensidade do torque no ponto de máxima coesão, com relação direta com a velocidade de rotação, mas que os tempos para atingir o ponto de máxima rigidez dos aglomerados foi quase sempre o mesmo (exceto 


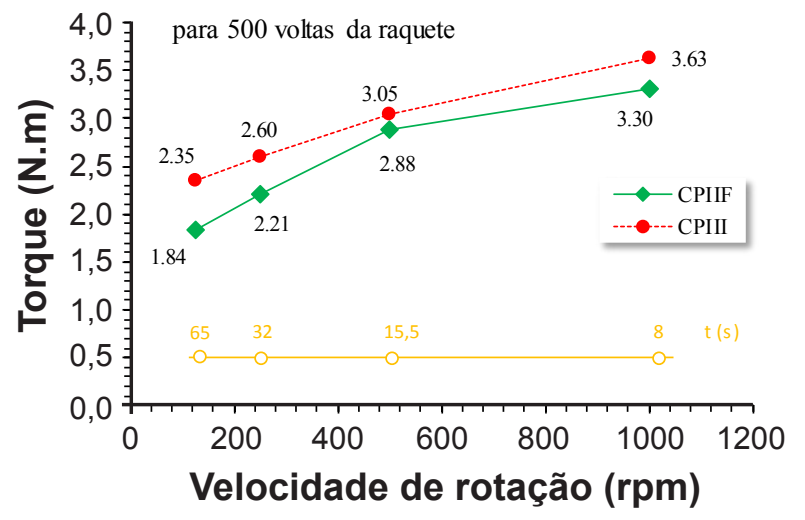

Figura 5: Torque das argamassas em função da velocidade de rotação para a mesma condição de cisalhamento: quantidade de voltas da raquete igual a 500. Em destaque são apresentados os tempos de mistura para atingir 500 voltas.

[Figure 5: Torque vs rotational speed for similar shear condition: revolution of padlle iqual to 500. Highlighted are presented the times of mix to reach 500 revolutions.]

para a mistura da argamassa com CPIIF a $125 \mathrm{rpm}$ ). Deve ser salientado que nas argamassas misturadas a $125 \mathrm{rpm}$ observou-se um pico de torque máximo seguido de uma queda brusca e um novo pico de aumento do torque; nestes casos, ficou claro que após atingir a máxima aglomeração, a água liberada durante o rompimento de parte dos aglomerados serviu para formar novos aglomerados com força de interação menor que a inicial, os quais foram rompidos com maior facilidade.

Após a adição da água no pó seco ocorreu a adsorção do líquido na superfície das partículas: nas mais finas, devido às forças de capilaridade e de van der Waals, houve formação dos aglomerados, que aprisionaram água em seu interior, diminuindo a quantidade de líquido para o seu afastamento. Este fenômeno, além de dificultar a fluidez do sistema e provocar o aumento inicial do torque, também afetou a capacidade de espumação dos aditivos, pois diminuiu a quantidade de água livre no sistema. Entretanto, no decorrer do ensaio e com a continuação do cisalhamento, os aglomerados foram rompidos e a quantidade de água livre no sistema aumentou, implicando em queda no torque e aumento do teor de ar incorporado, pois os aditivos incorporadores de ar necessitam de água e cisalhamento para iniciar a ação [17]. A determinação do ponto de fluidez de acordo com o método da primeira derivada [16] não indicou a constância do torque e, consequentemente, a adequação da consistência da argamassa, mas representou o tempo para que a argamassa seja considerada fluida, mesmo que a dispersão e homogeneização do sistema ainda não tenha sido completa; ou seja, caso o processo seja interrompido antes de atingir a estabilidade do torque, é possível que a argamassa ainda não esteja bem misturada e adequada para a aplicação.

Para todas as composições formuladas com CPIII, a energia dissipada durante o processamento foi maior que para as composições com CPIIF nas mesmas condições de ensaio. Este fato ocorreu em função da maior área superficial volumétrica do cimento com escória, que impactou diretamente na distância de separação entre os agregados e resultou na potencialização da aglomeração das partículas, dificultando o fluxo e o rompimento dos mesmos [1]. No entanto, após $180 \mathrm{~s}$ de mistura as argamassas já estavam homogêneas, visto que os torques apresentaram valores similares e independentes do tipo de cimento; ou seja, durante esta etapa a alteração na velocidade de rotação causou maior impacto no início da mistura, mas após o rompimento dos aglomerados formados rapidamente após a adição da água, a mesma consistência pôde ser atingida. Esse fato não indica que a microestrutura dos aglomerados seja a mesma, ou ainda, que as propriedades no estado endurecido serão.

Somente como critério comparativo, a Fig. 5 apresenta o impacto observado no torque quando a argamassa foi submetida a 500 voltas da raquete sobre o próprio eixo, ou seja, para distintos tempos de mistura em função da velocidade de rotação aplicada. Em destaque no gráfico estão os distintos tempos para atingir o número de voltas desejado em cada rotação. Adotou-se este número de voltas, pois em todos os casos o ponto de fluidez da argamassa já havia sido ultrapassado conforme ilustrado anteriormente na Fig. 4b. Para todas as velocidades de rotação impostas foi observado considerável diferença entre os torques das argamassas em função do tipo de cimento: em todos os casos o torque nas composições formuladas com o CPIII foi maior do que nas composições formuladas com o CPIIF, principalmente, conforme citado anteriormente, em função da maior área superficial volumétrica do ligante com escória. Aqui ficou claro que mesmo com partículas um pouco mais grossas que no cimento composto com filler, a maior ASE do ligante de escória afetou de forma mais acentuada a etapa de mistura. Como usualmente a mistura dos revestimentos industrializados nos canteiros de obra é mecanizada, argamassas com menor estimativa de energia de processamento necessita de menores tempos de batimento $\mathrm{e}$, consequentemente, resulta em ganhos de produtividade [4]. Além disso, materiais homogêneos apresentam menor incidência de manifestações patológicas, já que os aglomerados são pontos críticos, que reduzem a superfície disponível para a hidratação do cimento e possuem menor resistência mecânica, já que são elementos porosos.

\section{Estado endurecido}

A Fig. 6 apresenta o resultado da porosidade total das argamassas formuladas com os diferentes cimentos: em (a) estão ilustrados em função da porosidade total prevista (estimada a partir da soma entre o teor de ar incorporado no estado fresco e a quantidade de água de amassamento) e em (b) em função da velocidade da rotação. Os valores indicados pelos símbolos sem preenchimento na Fig. $6 \mathrm{~b}$ indicam a porosidade média obtida em cada caso. Na Fig. 6a o cruzamento dos dados indica a estabilidade do ar durante o enrijecimento: se os pontos estivessem localizados sobre a linha tracejada, poderia ser afirmado que houve estabilidade 

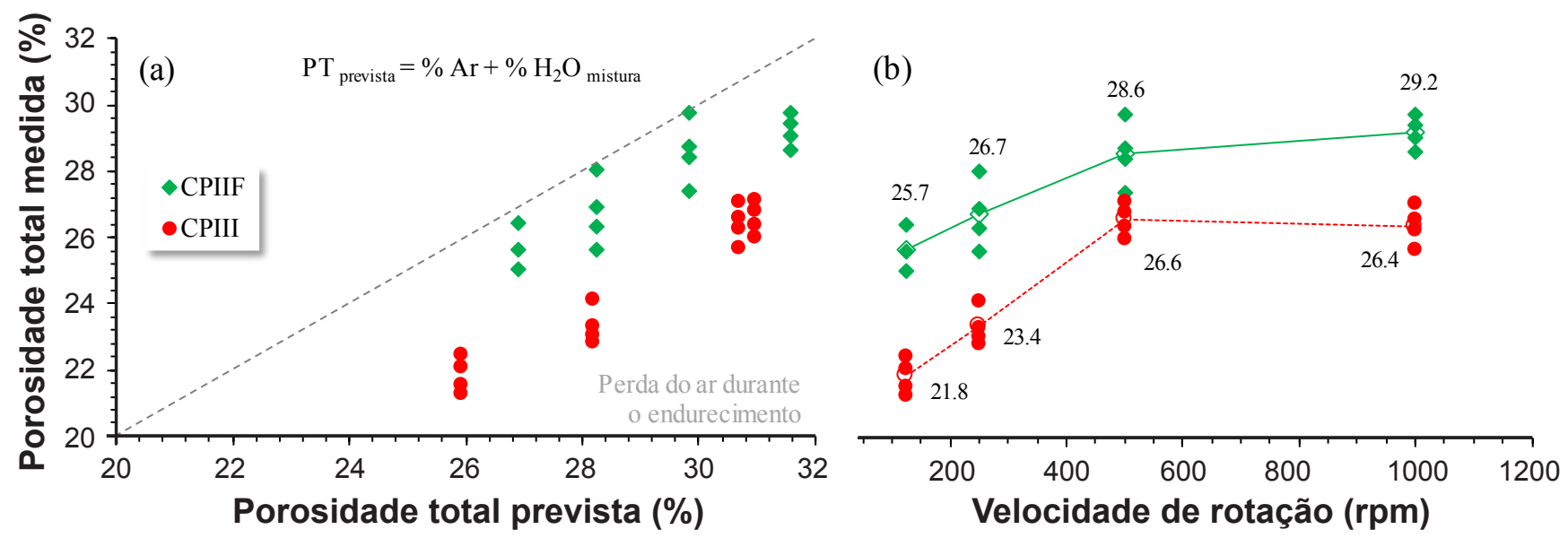

Figure 6: Variação da porosidade total das argamassas em função da porosidade total prevista (a) e da velocidade de rotação (b). Os valores indicam a porosidade média obtida.

[Figure 6: Total porosity of mortars as a function of the predicted total porosity (a), and rotational speed (b). The values indicate the average of obtained porosity.]

do ar intencionalmente incorporado durante a mistura. No entanto, constatou-se que o ar incorporado no estado fresco não apresentou boa estabilidade, principalmente nas argamassas formuladas com o cimento de escória. Neste caso houve uma diferença de cerca de $15 \%$ entre a porosidade prevista e a real, medida a partir do ensaio de imersão de Arquimedes. Sendo assim, as argamassas formuladas com CPIII apresentaram menor porosidade total em comparação às formuladas com CPIIF, visto que o teor de ar incorporado no estado fresco foi semelhante em ambos os casos. Não se pôde afirmar que existiu relação com o empacotamento das partículas, pois os valores estimados foram próximos (CPIIF 16,7\% e CPIII 16,4\%), mas uma hipótese levada em consideração foi que houve melhor compatibilidade entre o incorporador de ar utilizado e o cimento composto por filler calcário.

Para avaliação da significância da variação da velocidade de rotação na porosidade foi aplicada análise estatística de variância, Anova-fator único, com intervalo de confiança de $95 \%$, para rejeitar ou aceitar a hipótese da igualdade das médias, dentro e entre os grupos, e os resultados são apresentados nas Tabelas IV e V, respectivamente, para as amostras com o cimento CPIIF e CPIII. Na primeira parte da tabela são apresentadas as informações da quantidade de amostras avaliadas para cada velocidade de rotação, a soma dos resultados da porosidade, a média dos resultados e a variância em cada caso. No entanto, somente com esses resultados não foi possível avaliar se houve diferença estatística entre as amostras em relação à porosidade. Já a segunda parte trata da fonte de variação entre os grupos. O valor-P indica o valor de prova, e demonstra se a hipótese de igualdade entre os resultados referentes à variação da velocidade de rotação deve ser aceita ou rejeitada. Se o valor de prova for superior ao erro, ou seja 0,05 , deve-se aceitar, caso contrário, deve-se rejeitar a igualdade: nos casos avaliados, o valor foi muito inferior. Outra forma de se concluir se houve igualdade foi comparar o valor de F com F crítico: o F crítico limita a região de rejeição e significa que para valores de $\mathrm{F}$ superiores a hipótese da igualdade deve ser rejeitada. Portanto, como o valor de $\mathrm{F}$ foi maior do que o de F crítico em ambos os casos, houve confirmação de que a alteração da velocidade de rotação resultou em aumento da porosidade total, e o valor-P menor do que 0,05 comprovou a significância do resultado comparativo de $\mathrm{F}$ com F crítico. Sendo assim, pôde-se afirmar que as médias foram distintas e, portanto, a velocidade de rotação imposta na mistura afetou a formação da microestrutura porosa das composições, independentemente do tipo de cimento analisado. Adicionalmente, para a avaliação do impacto do tipo de cimento foi realizado o teste-z para cada velocidade de rotação, e os resultados são ilustrados na Tabela VI. Em todos os casos o valor de $\mathrm{z}_{\text {crítico }}$ foi menor do que de $\mathrm{z}_{\text {calculado }}$, indicando que o tipo de cimento, assim como no caso anterior, também afetou a formação da microestrutura porosa.

Como, de acordo com a literatura, pode-se afirmar que: i) os poros presentes na matriz cimentícia são oriundos da evaporação da água de amassamento e das bolhas de ar intencionalmente geradas durante o processamento; e ii) a porosidade apresenta relação com a resistência mecânica, com o módulo de elasticidade e com a permeabilidade ao ar, propriedades que definem o desempenho e a durabilidade do revestimento em uso, o controle do ar durante o estado fresco e, consequentemente, da porosidade resultante após o enrijecimento, pode representar menor variabilidade nas propriedades no estado endurecido. A porosidade resultante após o enrijecimento, que ao mesmo tempo é considerada benéfica para redução do módulo de elasticidade, pois tende a permitir uma melhor acomodação dos esforços impostos à estrutura e diminuir a ocorrência de fissuras, pode representar defeitos críticos que diminuem a resistência mecânica e a durabilidade do revestimento. Assim sendo, deve-se destacar que a porosidade e o módulo de elasticidade da argamassa devem ser projetados em uma determinada faixa que atenda aos requisitos de desempenho do sistema de revestimento. Na Fig. 7 são apresentados os resultados de resistência à 
Tabela IV - Análise estatística para avaliação da significância da velocidade de rotação na formação da microestrutura porosa nas argamassas com o cimento CPIIF.

[Table IV - ANOVA test as a function of the rotation speed on mortar's microstructure with cement CPIIF.]

\begin{tabular}{|c|c|c|c|c|c|}
\hline Grupo & Contagem & \multicolumn{2}{|c|}{ Soma } & Média & Variância \\
\hline 125 & 3 & \multicolumn{2}{|c|}{77,08} & 25,69 & 0,52 \\
\hline 250 & 4 & \multicolumn{2}{|c|}{106,94} & 26,74 & 1,04 \\
\hline 500 & 4 & \multicolumn{2}{|c|}{114,37} & 28,59 & 0,95 \\
\hline 1000 & 4 & \multicolumn{2}{|c|}{116,94} & 29,24 & 0,24 \\
\hline $\begin{array}{l}\text { Fonte de } \\
\text { variação }\end{array}$ & SQ & $\mathrm{gl}$ & MQ & $\mathrm{F}_{\text {calc }}$ & Valor-P $\quad \mathrm{F}_{\text {critic }}$ \\
\hline $\begin{array}{l}\text { Entre } \\
\text { grupos }\end{array}$ & 28,41 & 3 & 9,47 & 13,50 & $0,0005 \quad 3,59$ \\
\hline $\begin{array}{l}\text { Dentro dos } \\
\text { grupos }\end{array}$ & 7,72 & 11 & 0,70 & & \\
\hline Total & 36,13 & 14 & & & \\
\hline
\end{tabular}

Tabela V - Análise estatística para avaliação da significância da velocidade de rotação na formação da microestrutura porosa nas argamassas com o cimento CPIII.

[Table V-ANOVA test as a function of the rotation speed on mortar's microstructure with cement CPIII.]

\begin{tabular}{|c|c|c|c|c|c|c|}
\hline Grupo & \multicolumn{2}{|c|}{ Quantidade } & Soma & Média & \multicolumn{2}{|c|}{ Variância } \\
\hline 125 & 4 & & 87,40 & 21,85 & & 30 \\
\hline 250 & 4 & & 93,40 & 23,35 & & 32 \\
\hline 500 & 4 & & 106,34 & 26,59 & & 24 \\
\hline 1000 & 4 & & 105,62 & 26,40 & & 36 \\
\hline $\begin{array}{l}\text { Fonte de } \\
\text { variação }\end{array}$ & SQ & $\mathrm{gl}$ & MQ & $\mathrm{F}_{\text {calc }}$ & Valor-P & $\mathrm{F}_{\text {critic }}$ \\
\hline $\begin{array}{l}\text { Entre } \\
\text { grupos }\end{array}$ & 65,26 & 3 & 21,75 & 71,57 & $6,3 e-8$ & 3,49 \\
\hline $\begin{array}{l}\text { Dentro dos } \\
\text { grupos }\end{array}$ & 3,65 & 12 & 0,30 & & & \\
\hline Total & 68,90 & 15 & & & & \\
\hline
\end{tabular}

Tabela VI - Avaliação comparativa da significância dos resultados de porosidade para cada velocidade de rotação utilizada na mistura.

[Table VI - Comparative evaluation of the significance of the porosity results for each rotation speed used in the mixture.]

\begin{tabular}{|c|c|c|c|c|c|c|c|c|}
\hline \multirow[t]{2}{*}{ Velocidade de rotação } & \multicolumn{2}{|c|}{$125 \mathrm{rpm}$} & \multicolumn{2}{|c|}{$250 \mathrm{rpm}$} & \multicolumn{2}{|c|}{$500 \mathrm{rpm}$} & \multicolumn{2}{|c|}{$1000 \mathrm{rpm}$} \\
\hline & CPIIF & CPIII & CPIIF & CPIII & CPIIF & CPIII & CPIIF & CPIII \\
\hline Média & 25,69 & 21,85 & 26,74 & 23,35 & 28,59 & 26,58 & 29,24 & 26,40 \\
\hline Variância conhecida & 0,52 & 0,30 & 1,03 & 0,32 & 0,95 & 0,24 & 0,24 & 0,36 \\
\hline Observações & 3 & 4 & 4 & 4 & 4 & 4 & 4 & 4 \\
\hline Hipótese da diferença entre as médias & 0 & & 0 & & 0 & & 0 & \\
\hline $\mathrm{Z}$ calculado & 7,71 & & 5,82 & & 3,68 & & 7,31 & \\
\hline $\mathrm{P}(\mathrm{Z} \leq \mathrm{z})$ unicaudal & $6,11 \mathrm{e}^{-15}$ & & $2,82 \mathrm{e}^{-9}$ & & 0,0001 & & $1,33 \mathrm{e}^{-13}$ & \\
\hline z crítico unicaudal & 1,64 & & 1,64 & & 1,64 & & 2,32 & \\
\hline $\mathrm{P}(\mathrm{Z} \leq \mathrm{z})$ bicaudal & $1,22 \mathrm{e}^{-14}$ & & $5,64 \mathrm{e}^{-9}$ & & 0,0002 & & $2,66 \mathrm{e}^{-13}$ & \\
\hline z crítico bicaudal & 1,96 & & 1,96 & & 1,96 & & 2,58 & \\
\hline
\end{tabular}

tração na compressão diametral (a) e módulo de elasticidade dinâmico (b) em função da velocidade de rotação imposta durante a mistura.

As propriedades das argamassas no estado endurecido sofrem influência da pasta cimentícia, a qual é fortemente afetada pelo teor e tipo de ligante, pelo teor de ar incorporado, quantidade de água de amassamento, etc. [1]. Houve diferença no módulo de elasticidade das argamassas, tanto em função da velocidade de rotação quanto do tipo de cimento. As argamassas dosadas com o CPIII apresentaram rigidez maior do que as formuladas com CPIIF, no entanto este fato deve ser associado à alteração na porosidade total resultante das composições. É importante salientar que o impacto da velocidade de rotação foi observado somente até 500 rpm. Essa avaliação é importante para a caracterização do desempenho do revestimento, pois a partir dos resultados do módulo pode-se estimar a adequação da argamassa de revestimento frente às solicitações impostas à estrutura, sem que haja a formação de fissuras.

A permeabilidade pode ser adotada para a avaliação da durabilidade dos materiais cimentícios, pois possui relação com a microestrutura porosa das argamassas [18]. A formação da microestrutura foi influenciada pela velocidade de rotação adotada na mistura e, por este motivo, os valores de $\mathrm{k}_{1}$ (constante de permeabilidade darcyana) foram relacionados com a velocidade de rotação imposta durante a mistura. Os resultados são apresentados na Fig. 8. As argamassas formuladas com o cimento CPIII apresentaram menor estabilidade do ar incorporado e, consequentemente, a permeabilidade ao ar foi menor em comparação com as argamassas formuladas com o CPIIF. A partir dos resultados de permeabilidade foi possível constatar maior sensibilidade das argamassas com cimento CPIIF em função da variação da velocidade de rotação. Os valores de $\mathrm{k}_{1}$ apresentaram 

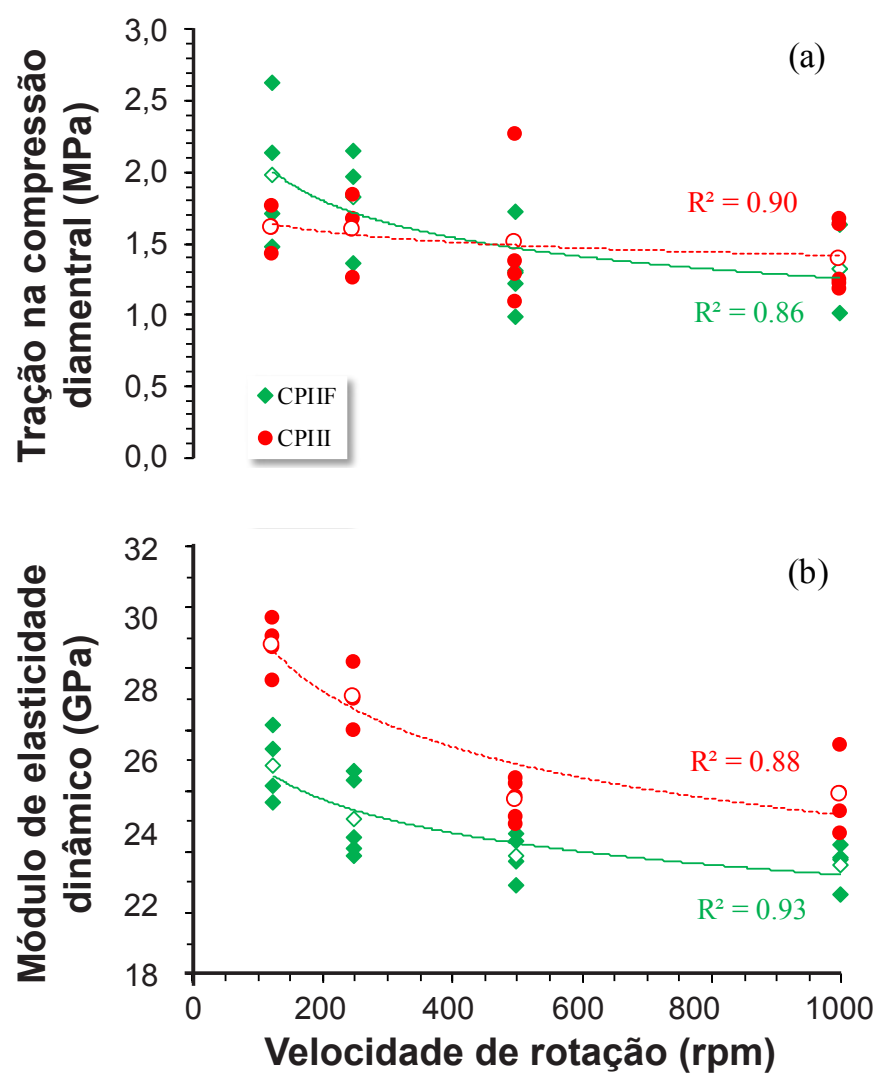

Figura 7: Variação da resistência à tração na compressão diametral (a) e do módulo de elasticidade dinâmico (b) em função da variação da velocidade de rotação imposta durante a mistura.

[Figure 7: Tensile strength in diametrical compression (a) and dynamic elasticity modulus $(b)$ as a function of the variation of the rotational speed imposed during the mixing.]

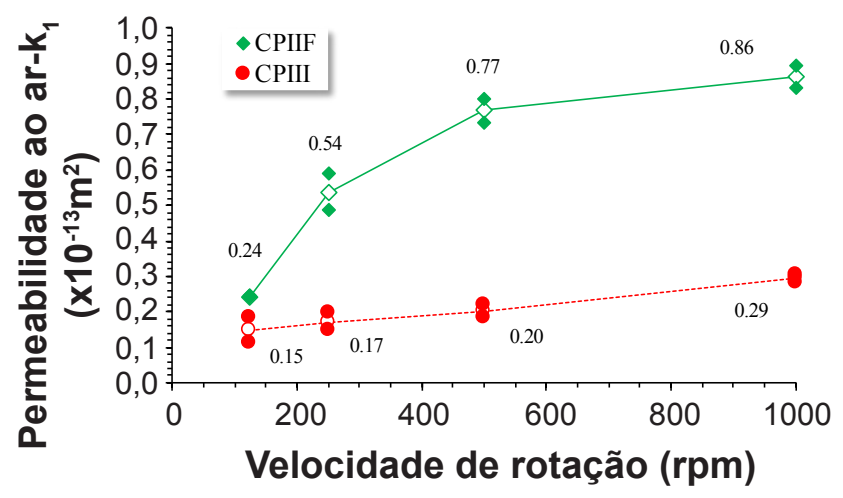

Figure 8: Permeabilidade ao ar $\left(\mathrm{k}_{1}\right)$ em função da variação da velocidade de rotação imposta durante a mistura.

[Figure 8: Air-permeability $\left(k_{1}\right)$ as a function of the variation of rotational speed imposed during the mixing.]

aumento de mais de $250 \%$ quando comparadas as argamassas misturadas em $1000 \mathrm{rpm}$ com as misturadas em $125 \mathrm{rpm}$. No caso das argamassas formuladas com CPIII, essa variação foi de quase $100 \%$.

A análise estatística de variância apontou que a hipótese de igualdade entre os resultados de permeabilidade em função da variação da velocidade de rotação deve ser descartada tanto para as argamassas formuladas com o CPIIF quanto com o CPIII. No entanto, a análise comparativa entre pares indicou que no caso das argamassas com CPIIF todas as velocidades resultaram em valores de $\mathrm{k}_{1}$ distintos entre si, mas para o cimento CPIII as argamassas misturadas com velocidade de até $500 \mathrm{rpm}$ foram similares entre si e distintas da amostra misturada a $1000 \mathrm{rpm}$. Essa diferença proporcionada pelo tipo de cimento ocorreu devido à maior instabilidade do ar durante o endurecimento nas composições com o CPIII, em função do pior sinergismo aditivo-escória. Nestas argamassas houve menor porosidade e consequente diminuição da conectividade entre os poros, fato que impactou diretamente na permeabilidade ao ar. A possibilidade de maior durabilidade nos revestimentos formulados com o cimento CPIII frente à ação dos agentes degradantes não deve ser creditada ao uso do cimento de escória, e sim às alterações na porosidade em função da instabilidade do ar. Possivelmente a utilização de um aditivo com melhor compatibilidade com o cimento de escória poderia favorecer a estabilidade do ar incorporado, o que aumentaria sua permeabilidade ao ar.

\section{CONCLUSÕES}

O tipo de cimento teve impacto distinto na incorporação de ar e na estimativa da energia necessária para o processamento das argamassas de revestimento avaliadas. No caso da porosidade, apesar do considerável aumento até a rotação de $500 \mathrm{rpm}$, a variação foi menos acentuada após esta velocidade e, no caso das argamassas com CPIII, o valor médio permaneceu praticamente constante. Esse fato pôde ser creditado à menor estabilidade do ar nas composições com o cimento de escória. A perda de ar durante o enrijecimento foi maior nas argamassas formuladas com o cimento de escória do que com o cimento com filler e as propriedades no estado endurecido foram afetadas pela alteração da porosidade resultante. Os resultados de resistência à tração na compressão diametral não permitiram diferenciar o impacto nem da velocidade de rotação nem do tipo de cimento. Já para o caso da permeabilidade ao ar, a maior sensibilidade do método permitiu visualizar melhor o impacto da variável de processamento e do tipo de cimento, sendo as argamassas com CPIII menos susceptíveis à ação dos agentes de degradação. Entretanto, essa diferença não deve ser creditada ao uso do cimento de escória, e sim às alterações na porosidade em função da instabilidade do ar nesses sistemas.

\section{AGRADECIMENTOS}

Os autores agradecem ao $\mathrm{CNPq}$ e ao Laboratório de Microestrutura e Ecoeficiência de Materiais da Escola Politécnica da USP, pelo apoio durante a realização do trabalho.

\section{REFERÊNCIAS}

[1] R.C.O. Romano, "Incorporação de ar em materiais 
cimentícios aplicados em construção civil", Tese Dr., Univ. S. Paulo, S. Paulo (2013).

[2] C.F. Ferraris, J. Res. Natl. Inst. Stand. Technol. 106, 2 (2001) 390.

[3] L. Du, K J. Folliard, Cem. Concr. Res. 35, 8 (2005) 1463. [4] R.C.O. Romano, H. Schreurs, F.B. Silva, F.A. Cardoso, M.M.S.B. Barros, R.G. Pileggi, V.M. John, Ambient. Constr. (Online) 9 (2009) 109.

[5] M.S. França, F.A. Cardoso, R.G. Pileggi, Ambient. Constr. (Online) 12, 2 (2012) 165.

[6] M. Yang, H.M. Jennings, Adv. Cem. Based Mater. 2 (1995) 70 .

[7] R.C.O. Romano, R.G. Pileggi, Appl. Rheology 22 (2012) 24333.

[8] Assoc. Brasil. Normas Téc., NBR 7214/15, “Areia normal para ensaio de cimento - especificação", Rio de Janeiro, (2015).

[9] Assoc. Brasil. Normas Téc., NBR 13278/02, “Argamassa para assentamento em paredes e revestimentos de paredes e tetos: determinação da densidade de massa e do teor de ar incorporado: método de ensaio", Rio de Janeiro (2002).

[10] Assoc. Brasil. Normas Téc., NBR 15630/09, "Argamassa para assentamento e revestimento de paredes e tetos - determinação do módulo de elasticidade dinâmico através da propagação de onda ultrassônica", Rio de Janeiro (2009).

[11] Assoc. Brasil. Normas Téc., NBR 7222/11, “Concreto e argamassa - determinação da resistência à tração por compressão diametral de corpos de prova cilíndricos", Rio de Janeiro (2011).

[12] R.J. Torrent, Mater. Struct. 25 (1992) 358.

[13] R.J. Torrent, G. Frenzer, "Methods for measuring and assessing the characteristics of the concrete cover on site", Report \# 516, Office Fedéral des Routes, Zurich (1995).

[14] M.D.M. Innocentini, A.R.F. Pardo, V.R. Salvini, V.C. Pandolfeli, Cerâmica 48, 305 (2002) 5.

[15] M.D.M. Innocentini, V.P. Rodrigues, R.C.O. Romano, R.G. Pileggi, G.M.C. Silva, J.R. Coury, J. Hazard. Mater. 162 (2009) 212.

[16] M.S. França, "Comportamento de mistura de sistemas cimentícios multifásicos reativos”, Diss. Mestr., Univ. S. Paulo, S. Paulo (2013).

[17] D.R. Torres, A.L. Fujii, R.C.O. Romano, R.G. Pileggi, in: VII Simpósio Brasileiro de Tecnologia das Argamassas, Fortaleza (2013).

[18] S. Care, F. Derkx, Constr. Buil. Mater. 25 (2011) 1248. (Rec. 22/11/2016, Rev. 16/01/2017, Ac. 22/02/2017) 